\section{Survival rates of advanced estrogen-receptor positive breast cancer. Analysis of 211 cases}

\author{
CÉSAR SÁNCHEZ1, FRANCISCO DOMÍNGUEZ², \\ HÉCTOR GALINDO ${ }^{1}$, MAURICIO CAMUS ${ }^{2}$, DAVID ODDO ${ }^{3}$, \\ ALEJANDRA VILLARROEL ${ }^{3}$, DRAVNA RAZMILIC ${ }^{4}$, JOSÉ PEÑA ${ }^{1}$, \\ MARÍA ELENA NAVARRO ${ }^{4}$, LIDIA MEDINA ${ }^{5}$, TOMÁS MERINO ${ }^{1}$, \\ JUAN BRIONES ${ }^{1}$, FRANCISCO ACEVEDO ${ }^{1}$
}

\begin{abstract}
Background: About $80 \%$ of breast cancer (BC) cases express estrogen receptor (ER), which has been correlated with good prognosis and response to estrogen deprivation Aim: To characterize ER positive advanced $B C(A B C)$ patients treated at our institution assessing the impact of clinical presentation (stage $I V$, de novo disease at diagnosis versus systemic recurrence) and BC subtype on survival rates. Material and Methods: We evaluated $211 E R+$ advanced $B C(A B C)$ patients, treated between 1997 and 2017. Results: The median overall survival (OS) was 37 months. Median OS for the period 1997/2006 and 2007/2017 were 33 and 42 months, respectively ( $p=0.47)$. Luminal $A, A B C$ stage IV disease at diagnosis displayed better OS rates than Luminal B stage IV tumors (100 and 32 months respectively, $p<0.01$ ). Conclusions: Clinical presentation (stage IV vs. systemic recurrence) and tumor subtype are key determinants of $O S$ in $A B C$.

(Rev Med Chile 2020; 148: 1233-1238)
\end{abstract}

Key words: Breast Neoplasms; Neoplasm Metastasis; Prognosis; Receptors, Estrogen.

\section{Sobrevida de pacientes con cáncer de mama avanzado positivo para receptores de estrógenos}

Antecedentes: Casi el 80\% de los casos de cáncer de mama (CM) son positivos para receptores de estrógenos (RE+). Éstos se caracterizan por una mejor sobrevida y respuesta a terapia endocrina. Objetivo: Caracterizar a pacientes con CM avanzado (CMA), RE+, y determinar sobrevida según presentación clínica y subtipos. Material y Métodos: Analizamos en nuestra base de datos los antecedentes de 211 pacientes con CMA RE+, tratados en nuestra institución en el período 1997-2017. Se evaluó el impacto de la presentación clínica (estadio IV al diagnóstico, enfermedad de novo, versus recurrencia sistémica) y subtipo de CM, en los niveles de sobrevida. Resultados: La mediana de sobrevida global (SG) fue de 37 meses. La mediana de SG para el período 1997/2006 y 2007/2017 fue de 33 y 42 meses; respectivamente $(p=0,47)$. Pacientes con CMA, estadio $I V$, Luminal A al momento del diagnóstico mostraron mejores tasas de SG frente al estadio IV del Luminal B (100 y 32 meses respectivamente $(p<0,01)$. Conclusiones: La presentación clínica (estadio IV, de novo, versus recurrencia sistémica) y subtipo son determinantes clave de la SG en CMA.

Palabras clave: Estrógenos; Neoplasias de la Mama; Metástasis de la Neoplasia; Pronóstico.
'Departamento de HematologíaOncología. Escuela de Medicina. Pontificia Universidad Católica de Chile, Santiago, Chile.

${ }^{2}$ Departamento de Cirugía Oncológica y Maxilofacial. Escuela de Medicina. Pontificia Universidad Católica de Chile,

Santiago, Chile.

${ }^{3}$ Departamento de Anatomía-

Patológica. Escuela de Medicina.

Pontificia Universidad Católica de

Chile, Santiago, Chile.

${ }^{4}$ Departamento de Radiología.

Escuela de Medicina. Pontificia

Universidad Católica de Chile,

Santiago, Chile.

${ }^{5}$ Centro de Cáncer. Pontificia Universidad Católica de Chile,

Santiago, Chile.

Funding Statement: Work was partially funded by a FONDECYT iniciacion grant \# 11161103 (CS).

Recibido el 13 de mayo de 2020 aceptado el 14 de agosto de 2020.

Correspondence:

Francisco Acevedo, MD

Departamento de Hematología-Oncología. Escuela de Medicina.

Pontificia Universidad Católica de Chile

Centro de cáncer.

Diagonal Paraguay 319.

Santiago 8330032. Chile. fnacevedo@gmail.cl 
W orldwide, Breast Cancer (BC) is the most frequently diagnosed cancer among women. In Chile, $\mathrm{BC}$ is the leading cause of cancer death ${ }^{1}$. As occurs with most malignancies $\mathrm{BC}$ prognosis depends on the stage of the disease but also on its subtype classification ${ }^{2}$. While early stage disease mammary neoplasias are frequently cured, advanced or systemic disease patients treatments are often limited to palliative care. In general, $<10 \%$ of BC patients are diagnosed at stage IV with metastatic disease and a $20-30 \%$ of patients with early stage disease display systemic recurrence ${ }^{3}$. Newly-diagnosed metastatic endocrine-responsive or recurrent tumors are commonly treated with endocrine therapy $(\mathrm{ET})^{4}$. The efficacy of ET is largely dependent on: specific tumor features, prior use of adjuvant/neoadjuvant therapies, and disease-free interval. Novel management strategies have improved therapy response and progression-free survival rates in these patients, maintaining aceptable levels of life quality. Alongside Tamoxifen, a selective estrogen receptor (ER) modulator other compounds such as aromatase inhibitors, fulvestrant (an anti-estrogen), and more recently small-molecule inhibitors have shown activity against these tumors ${ }^{5-7}$.

Here, we report survival rates of ER+ advanced $\mathrm{BC}(\mathrm{ABC})$ patients treated at our institution over the last 20 years, in order to characterize $\mathrm{ER}+$ advanced $\mathrm{BC}(\mathrm{ABC})$ patients treated at our institution assessing the impact of: clinical presentation (stage IV at diagnosis or de novo diseaseversus systemic recurrence) and $\mathrm{BC}$ subtype upon survival rates.

\section{Materials and Methods}

\section{Ethics approval and patients}

This was an observational, retrospective study. Our procedures respected ethical standards in accordance with the Declaration of Helsinki (updated in 2013) and were reviewed and approved by a Human Research Ethics Committee at our institution (School of Medicine, Pontificia Universidad Catolica de Chile, approval resol number: 200303006). Patients were treated between 1997 and September 2017 at the Cancer Center "Nuestra Señora de La Esperanza" in the Pontificia Universidad Catolica de Chile and the Red de Salud UC CHRISTUS. Only patients with advanced metastatic ER-positive disease were included in the study. They were further categorized as either: (a) being diagnosed with metastatic disease at diagnosis (stage IV at diagnosis or de novo disease group) or (b) being diagnosed with early disease but whom later developed a systemic or unresectable disease (systemic recurrence group). Clinical data analyzed included: Age, clinical presentation, recurrence status, calendar year at diagnosis and overall survival (OS), defined as the time period between the diagnosis of $\mathrm{ABC}$ (or recurrence) and the time of patient death by any cause.

\section{$B C$ subset and survival analyses}

Briefly, tumors were classified as Luminal A when they expressed ER and/or the Progesterone Receptor (PR) with a histological grade (HG) 1 or 2. Luminal B were $\mathrm{ER}+$ and/or $\mathrm{PR}+$ and $\mathrm{HG}=3$ or positive for the Human Epidermal growth factor Receptor type 2 (HER2) $)^{8,9}$; HER2+ was defined as Immunohistochemistry (IHQ) HER2 overexpression equal to $3+$ or by HER2 gene amplification measured by Fluorescent In Situ Hybridization (FISH) in IHQ2+ cases. As explained above, survival rates of patients were also analyzed according to the year of diagnosis, dividing into two groups: 1997-2006 and 2007-2017, in order to assess the impact of novel therapies and management strategies over the last decade. Data were analyzed by descriptive statistics; OS were calculated by the Kaplan-Meier method and curves were compared using the Log Rank test in the XLSTAT statistic software v. 19.4.

\section{Results}

Tumor subset information was available for 2,243 out of $2,724(82 \%)$ patients in our database. Within this group, a total of $1,828(81.4 \%)$ were classified as ER+: 1,082 (59\%) Luminal A and 746 (41\%) Luminal B (Figure 1).

Tumor stage was available for 1,766 patients and $82(4.6 \%)$ were stage IV at diagnosis. As explained, patient survival rates were analyzed over the last 20 years grouping patients by decades. Median follow-up was 104 and 23 months for decades 1 (period 1997-2006) and 2 (2007-2017), respectively; 129 displayed systemic recurrent or unresectable disease. Therefore, our study involved a total of $211 \mathrm{ER}+\mathrm{ABC}$ patients that were analyzed. Patient characteristics are summarized in Table 1; a 


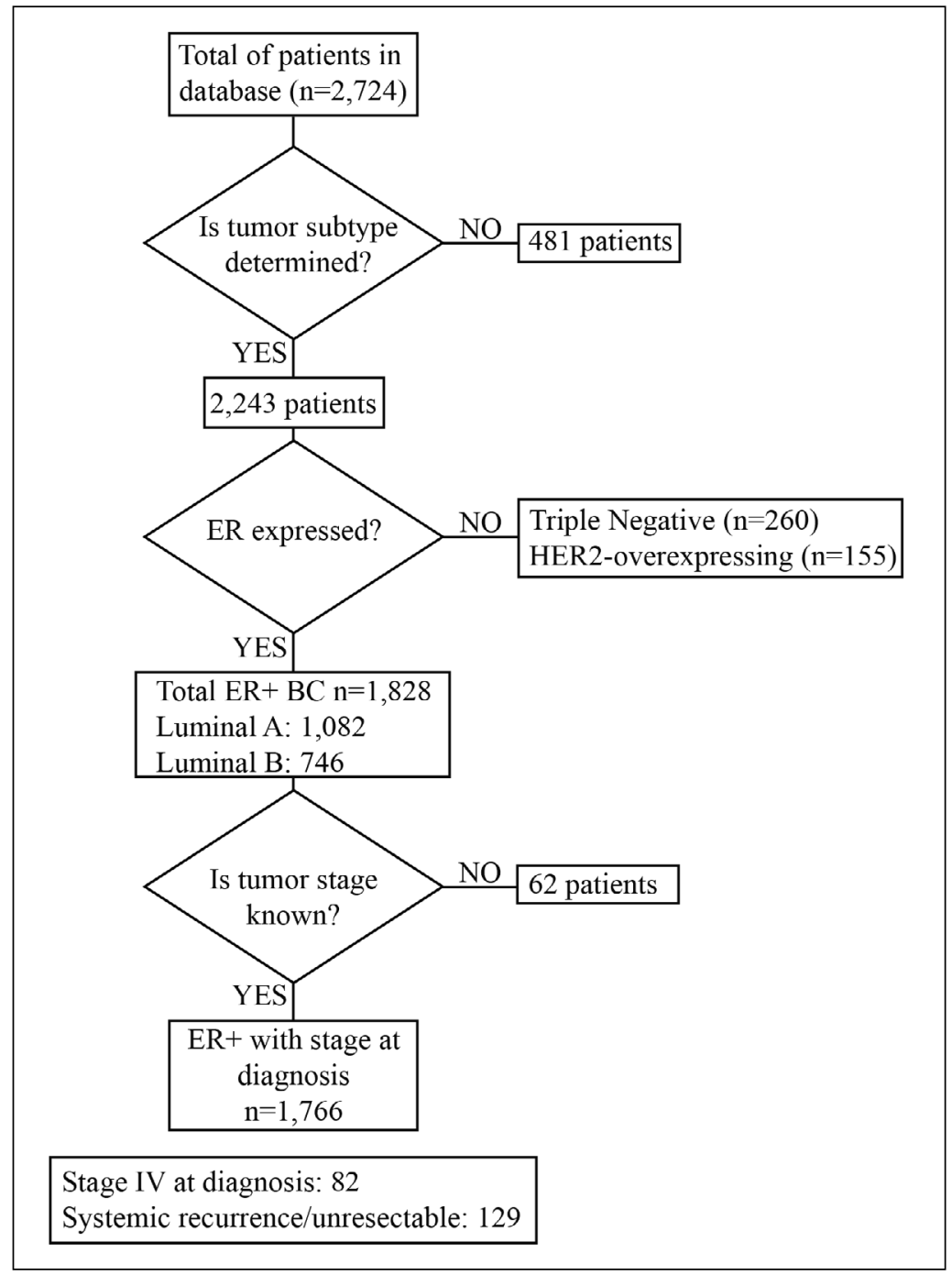

Figure 1.

$39 \%$ of ABCs were diagnosed at stage IV and $61 \%$ were systemic recurrences; group 2 (2007-2017) included more stage IV patients at diagnosis (54\% against 15\% in group 1: 1997-2006 period). Median OS for the entire group was 37 months (Figure 2A); differences in OS for patients with stage IV at diagnosis and patients with recurrent disease were statistically significant (51 against 33 months, respectively. $\mathrm{p}=0.008$. Figure $2 \mathrm{~B}$ ). Similarly, OS for Luminal A tumors was 63 months against 33 months in Luminal B ( $\mathrm{p}=0.004$, Figure 2C). According to their clinical presentation, OS for stage IV-Luminal A tumors was 100 months versus 32 months in stage IV-Luminal B. For recurrent tumors, OS in Luminal A and Luminal B was 34 and 33 months, respectively $(p=0.001$, Figure $2 D)$. When comparing the period 1997/2006 against the 2007-2017, OS was 33 and 42 months, respectively. However, these differences did not reach statistical significance $(p=0.47$, Figure $2 \mathrm{E})$. Regarding tumor subsets OS was higher over the 2 time periods for Luminal A versus Luminal B. 1997-2006 $=68$ months for Luminal A versus 27 months in Luminal B. 2007-2017 $=57$ months in Luminal A versus 37 months in Luminal B $(p=0.023)$. Finally, median OS for Luminal A and Luminal B along the above mentioned time periods did not reach statistical significance. 
Table 1. Demographic, clinical presentation, follow-up time and median oS rates of patients

\begin{tabular}{|lcccc|}
\hline & $\mathbf{1 9 9 7 - 2 0 0 6}$ & $\mathbf{2 0 0 7 - 2 0 1 7}$ & p-value & Total \\
\hline Patients $(\mathrm{n})$ & 81 & 130 & $\mathrm{~N} / \mathrm{A}$ & 211 \\
\hline Median age (years/range) & $51(25-81)$ & $53(19-88)$ & 0.23 & $\mathrm{~N} / \mathrm{A}$ \\
Clinical presentation (n) & & & & \\
$\quad$ Stage IV (de novo) & 12 & 70 & $<0.0001$ & $82(39 \%)$ \\
$\quad$ Recurrent disease & 69 & 60 & $\mathrm{~N} . \mathrm{S}$. & $129(61 \%)$ \\
Median follow-up (months) & 104 & 23 & $<0.0001$ & $\mathrm{~N} / \mathrm{A}$ \\
Median OS (months) & 33 & 42 & 0.47 & $\mathrm{~N} / \mathrm{A}$ \\
\hline
\end{tabular}

Abbreviations: N/A: not applicable, N.S.: Not significant, OS: Overall Survival.

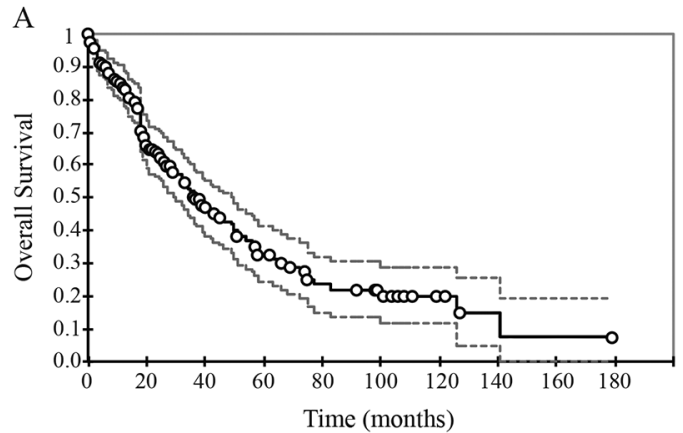

B

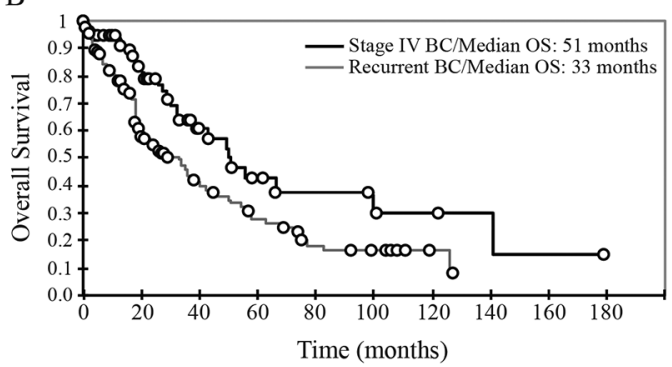

D

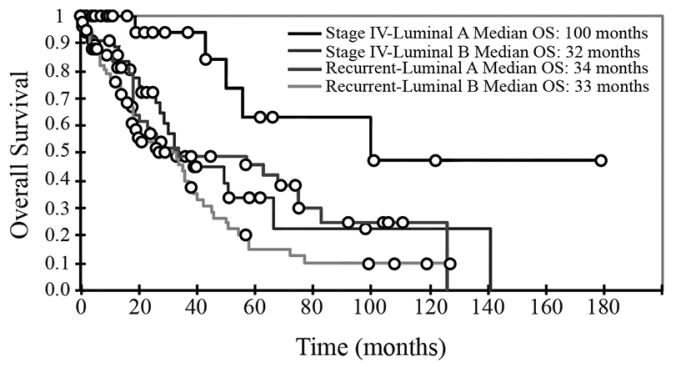

$\mathrm{C}$

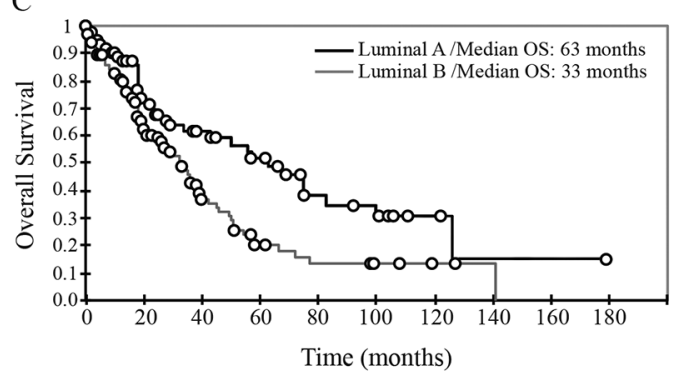

E

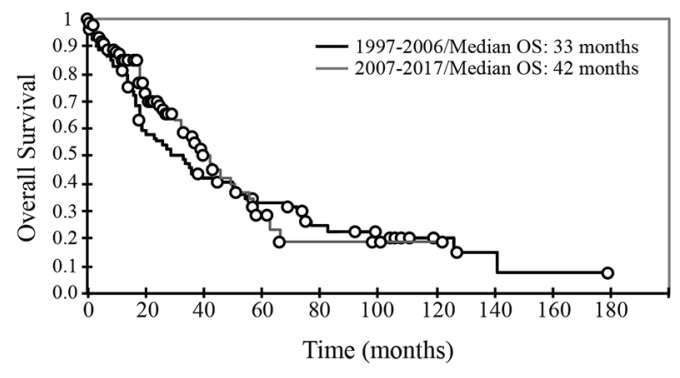

Figure 2. 


\section{Discussion}

Herein, we assessed changes in OS for advanced $\mathrm{ER}+\mathrm{BC}$ patients over the last 2 decades in a single institution. Our study focused on the prognosis of patients diagnosed at stage IV versus patients with recurrent disease, and its relationship with tumor subset. Overall, our data demonstrate an increase in OS during the most recent decade (42 against 33 months) that did not reach statistical significance. This is probably explained by a small sample size.

Remarkably, we found that patients with Luminal A tumors had OS rates that were almost three times higher compared to other ER+ subsets that also were metastatic at diagnosis (100 against 33 months, for Luminal A and Luminal B; respectively). Several studies have demonstrated a progressive improvement in OS over time for patients with advanced $\mathrm{BC}$ and differences in survival for patients with metastatic disease at diagnosis versus patients with late recurrences ${ }^{10,11}$. Indeed, Giordano (2004) analyzed a cohort of 834 advanced BC patients that recurred between 1974-2000, and demonstrated that median OS for patients diagnosed in the period 1974-1974 was 15 months versus 58 months for those diagnosed in the period 1995-2000, demonstrating a 1\% decrease in the risk of death ${ }^{12}$. Another study evaluated 724 women with stage IV disease at diagnosis and found that OS for patients diagnosed in the period 1987-1993 was 23 months versus 29 months in the period 1994-2000 $(\mathrm{p}<0.0001)^{13}$. A retrospective study analyzed data from a total of 3,524 ABC patients, 1974 were ER+ and $18 \%$ were stage IV. Median OS for stage IV patients was 39.2 months versus 27.2 for patients with recurrent disease $(p<0.0001)$. Interestingly, differences in OS between patients that developed recurrent disease after 5 years and stage IV patients were not significant ${ }^{14}$. More recently, another retrospective study assessed OS in $172 \mathrm{ER}+\mathrm{BC}$ patients, 65 were stage IV $(38 \%)$ and 107 displayed recurrent metastasis (62\%). Median OS rates were 4.85 and 3.45 years, respectively $(\mathrm{p}=0.046)$. Similarly, patients with late recurrence had better prognosis compared to those with a metastasis free interval (MFI) $<24$ months ${ }^{15}$. Next, using medical records from 815 patients Lobbezoo (2015) confirmed a better survival in patients with stage IV disease at diagnosis or with a MFI $>24$ months compared to patients with MFI $<24$ months (median OS 29.4 against 9.1 months, $\mathrm{p}=0.0001)^{16}$. Studies speculate that emergence of resistance derived from the exposure to one or more lines of therapy in patients with recurrent disease could explain poorer survival rates compared to patients with stage IV disease at diagnosis ${ }^{10,12}$.

In agreement with all the above mentioned studies OS rates of AER+ BC patients in our institution have improved over the last decade. Evidently, comparing OS rates over time presents a bias given by the improvement in cancer staging methods. Current imaging techniques allow the detection of a greater number of patients, especially those with systemic disease, with oligo-metastasis or with a relatively low disease burden and associated to a better prognosis ${ }^{17}$. Indeed, this could also explain the higher proportion of patients with $\mathrm{ABC}$ at diagnosis observed at our institution in recent years. Another factor is the variation in clinical follow-ups, in certain cases $\mathrm{ER}+\mathrm{BCs}$ can recur even decades after the initial diagnosis $^{5,18}$.

Biases of our work include loss of data, small sample size, definition of subsets based on immunohistochemistry and not according to molecular profiles and the uneven extension of follow-up in both groups.

The assessment of BC subset not only provides information on the natural history of the disease but also determines specific treatment options for patients. About $80 \%$ of all BC cases are categorized as luminal hormone-dependent, usually indolent and with a good prognosis ${ }^{19-21}$. Novel, more efficient therapies have progressively improve survival rates on $\mathrm{ER}+\mathrm{ABC}$ patients, in some cases maintaining a long-term stable disease and making it a chronic condition for certain patients ${ }^{6,20,22}$. As explained above, it is particularly relevant to discriminate between those advanced $\mathrm{BC}$ patients that were diagnosed at stage IV versus patients with recurrent disease, especially for those that participate in clinical trials. Likewise, it is crucial to determine the proportion of highly estrogen dependent tumors (Luminal A) versus those with a moderate response to ET (Luminal B) in order to analyze data and extrapolate results, particularly regarding the efficacy of the time of clinical follow up and its impact. 


\section{References}

1. https://www.uicc.org/news/new-global-cancer-data-globocan-2018 (consultado el 02-03-2020).

2. Balic M, Thomssen C, Würstlein R, Gnant M, Harbeck N. St. Gallen/Vienna 2019: A Brief Summary of the Consensus Discussion on the Optimal Primary Breast Cancer Treatment. Breast Care 2019; 14 (2): 103-10.

3. Pan H, Gray R, Braybrooke J, Davies C, Taylor C, McGale $\mathrm{P}$, et al. 20-Year Risks of Breast-Cancer Recurrence after Stopping Endocrine Therapy at 5 Years. N Engl J Med 2017; 377 (19): 1836-46.

4. Cardoso F, Costa A, Senkus E, Aapro M, André F, Barrios $\mathrm{CH}$, et al. Corrigendum: 3rd ESO-ESMO international consensus guidelines for Advanced Breast Cancer (ABC 3). Ann Oncol 2016; 28 (1): 16-33

5. Kennecke H, Yerushalmi R, Woods R, Cheang MCU, Voduc D, Speers CH, et al. Metastatic behavior of breast cancer subtypes. J Clin Oncol 2010; 28 (20): 3271-7.

6. Guarneri V, Conte P. Metastatic Breast Cancer: Therapeutic Options According to Molecular Subtypes and Prior Adjuvant Therapy. Oncologist 2009; 14 (7): 645-56.

7. Im S-A, Lu Y-S, Bardia A, Harbeck N, Colleoni M, Franke F, et al. Overall Survival with Ribociclib plus Endocrine Therapy in Breast Cancer. N Engl J Med 2019; 381 (4): 307-16.

8. Acevedo F, Camus M, Sanchez C. Breast Cancer at Extreme Ages - a Comparative Analysis in Chile. Asian Pac J Cancer Prev 2015; 16 (4): 1455-61.

9. Acevedo F, Camus M, Vial C, Panay S, Abarca M, Domínguez F, et al. Predictive value of conventional immuno-histochemical biomarkers in breast cancer. Rev Med Chile 2015; 143 (6): 724-32.

10. Dawood S, Broglio K, Gonzalez-Angulo AM, Buzdar AU, Hortobagyi GN, Giordano SH. Trends in Survival Over the Past Two Decades Among White and Black Patients With Newly Diagnosed Stage IV Breast Cancer. J Clin Oncol 2008; 26 (30): 4891-8.

11. Cardoso F, Senkus E, Costa A, Papadopoulos E, Aapro M, André F, et al. 4th ESO-ESMO International Consensus Guidelines for Advanced Breast Cancer (ABC 4) †. 2018 [cited 2020 Apr 28]; Available from: http://www.abc-lisbon. org/

12. Giordano SH, Buzdar AU, Smith TL, Kau S-W, Yang Y, Hortobagyi GN. Is breast cancer survival improving? Can- cer 2004; 100 (1): 44-52.

13. Andre F, Slimane K, Bachelot T, Dunant A, Namer M, Barrelier A, et al. Breast Cancer With Synchronous Metastases: Trends in Survival During a 14-Year Period. J Clin Oncol 2004; 22 (16): 3302-8.

14. Dawood S, Broglio K, Ensor J, Hortobagyi GN, Giordano $\mathrm{SH}$. Survival differences among women with de novo stage IV and relapsed breast cancer. Ann Oncol 2010; 21 (11): 2169-74.

15. Yamamura J, Kamigaki S, Fujita J, Osato H, Komoike Y. The Difference in Prognostic Outcomes Between De Novo Stage IV and Recurrent Metastatic Patients with Hormone Receptor-positive, HER2-negative Breast Cancer. In Vivo 2018; 32 (2): 353-8.

16. Lobbezoo DJA, van Kampen RJW, Voogd AC, Dercksen MW, van den Berkmortel F, Smilde TJ, et al. Prognosis of metastatic breast cancer: are there differences between patients with de novo and recurrent metastatic breast cancer? Br J Cancer 2015; 112 (9): 1445-51.

17. Sledge GW. Curing Metastatic Breast Cancer. J Oncol Pract 2016; 12 (1): 6-10.

18. Lim E, Metzger-Filho O, Winer EP. The natural history of hormone receptor-positive breast cancer. Oncology (Williston Park, N.Y.) 2012; 26 (8): 688-94.

19. Coates AS, Winer EP, Goldhirsch A, Gelber RD, Gnant M, Piccart-Gebhart M, et al. Tailoring therapies-improving the management of early breast cancer: St Gallen International Expert Consensus on the Primary Therapy of Early Breast Cancer 2015. Ann Oncol 2015; 26 (8): 1533-46.

20. Goldhirsch A, Wood WC, Coates AS, Gelber RD, Thürlimann B, Senn H-J. Strategies for subtypes-dealing with the diversity of breast cancer: highlights of the St. Gallen International Expert Consensus on the Primary Therapy of Early Breast Cancer 2011. Ann Oncol 2011; 22 (8): 1736-47.

21. Goldhirsch A, Winer EP, Coates AS, Gelber RD, Piccart-Gebhart M, Thürlimann B, et al. Personalizing the treatment of women with early breast cancer: Highlights of the st gallen international expert consensus on the primary therapy of early breast Cancer 2013. Ann Oncol 2013; 24 (9): 2206-23.

22. Chlebowski RT. Changing concepts of hormone receptor-positive advanced breast cancer therapy. Clinical Breast Cancer 2013; 13(3): 159-66. 